\title{
Detection of aflatoxins and zearalenone contamination in wheat derived products
}

\begin{abstract}
In present study the natural occurrence of aflatoxins (AFs) and zearalenone (ZEN) has determined in 147 samples of wheat derived products i.e. spaghetti (25), noodles (34), macaroni (29), lasagne (37), and bucatini (22), collected from major districts of Punjab, Pakistan. The mean of AFs was found 9.12 in spaghetti, 7.35 in noodles, 5.91 in macaroni, 8.39 in lasagne, and $9.61 \mu \mathrm{g} / \mathrm{kg}$ in bucatini and $28,18,17,22$ and $27 \%$ of samples were found above the European Union's legal limit (i.e. $4 \mu \mathrm{g} / \mathrm{kg}$ ) for total AFs, respectively. However, mean value of ZEN was found 7.36 in spaghetti, 6.80 in noodles, 4.98 in macaroni, 6.90 in lasagne, and $8.89 \mu \mathrm{g} / \mathrm{kg}$ in bucatini samples and $16,15,21,19$ and $36 \%$ of samples were found to be above the recommended limit. The study urged the need to focus more comprehensive survey for these toxins in wheat derived products from Punjab, Pakistan.
\end{abstract}

Keyword: Aflatoxins; Zearalenone; RP-HPLC; Wheat products 